\title{
Materials with electronic transitions in the near-infrared
}

\author{
WOLFGANG KAIM \\ Institut für Anorganische Chemie, Universität Stuttgart, Pfaffenwaldring 55, 70550 Stuttgart, Germany \\ E-mail: kaim@iac.uni-stuttgart.de
}

MS received 28 February 2019; revised 13 May 2019; accepted 15 May 2019; published online 10 October 2019

\begin{abstract}
Concepts have been developed which favor low-energy absorption in the near-infrared (NIR) region. These include metal-metal charge transfer (inter-valence charge transfer) transitions of mixed-valent species, radical ion compounds (anions, cations), and mixtures thereof. Recent examples from ruthenium coordination chemistry are presented in order to illustrate analysis and assignment of such NIR transitions.
\end{abstract}

Keywords. Charge transfer; mixed valency; near-infrared; radical complexes; Ruthenium compounds.

\section{Introduction}

Near-infrared radiation was detected as 'calorific rays' around 1800 by Friedrich Wilhelm (Sir Frederick William) Herschel (1738-1822); the discoverer of the first non-classical planet, Uranus. Materials with absorptions in the NIR region, between 800 and 2500 $\mathrm{nm}\left(12500-4000 \mathrm{~cm}^{-1}\right)$, were little studied at first, partly because of the rarity and the cost of corresponding spectrometers. However, several recent developments of more facile NIR detection have spurned a growth of corresponding research, related to the following emerging areas of application:

- Telecommunications using glass fiber optics (Nobel Prize in Physics 2009 for C. K. Kao) relies on nearinfrared wavelength ranges which ensure minimal attenuation of optical signals. ${ }^{1}$

- Bio-imaging and -sensing uses the near-infrared region due to the absorption specifics of tissue. The latter is also employed for thermal and photodynamic therapy. ${ }^{2}$

- Atmospheric analysis in the near-infrared relies partially on sensitive devices operating in that wavelength region. ${ }^{3}$

- Analysis of complex mixtures such as food has been greatly boosted by the application of databasesupported near-infrared spectroscopy. ${ }^{4}$

Near-infrared absorbing materials, whether organic, organometallic or inorganic, have often been

*For correspondence discovered without support by a systematic approach. In contrast to numerous low-bandgap analyses for solid-state structures (semiconductors, polymers, charge transfer compounds from discrete molecules), ${ }^{5}$ there have been few attempts to classify small molecular compounds with low energy absorbance. ${ }^{6-9}$

Among the functions resulting in NIR absorption are high-energy vibrational absorption features (overtones), e.g., from O-H groups, low-energy $\pi-\pi$ type absorptions from radicals or mixed-valent species, ${ }^{7}$ or $f$ - $f$ transitions. The latter are weak as absorptions but play an important role in NIR emission, ${ }^{10}$ as do certain transition metal compounds. ${ }^{11}$ In the following, the origin of NIR absorption and the interplay between radical ligands and mixed-valent dimetal combinations will be outlined for coordination compounds of ruthenium.

\section{Results and Discussion}

Radicals and radical ions have long been recognized as chromophores in the low energy region, i.e., in the nearinfrared. ${ }^{12}$ A straightforward explanation ${ }^{7}$ starts from the typically large HOMO-LUMO gap of stable molecules with a high energy transition between these frontier orbitals. One-electron oxidation may then create an empty site at the HOMO to which a low-energy transition from other filled orbitals can occur. Conversely, the additional electron introduced to the LUMO through one-electron reduction can be excited to other close-lying unoccupied orbitals, resulting also in a low-energy absorption.

Near-infrared absorption caused by such excitation mechanisms can be enhanced electronically and sterically 


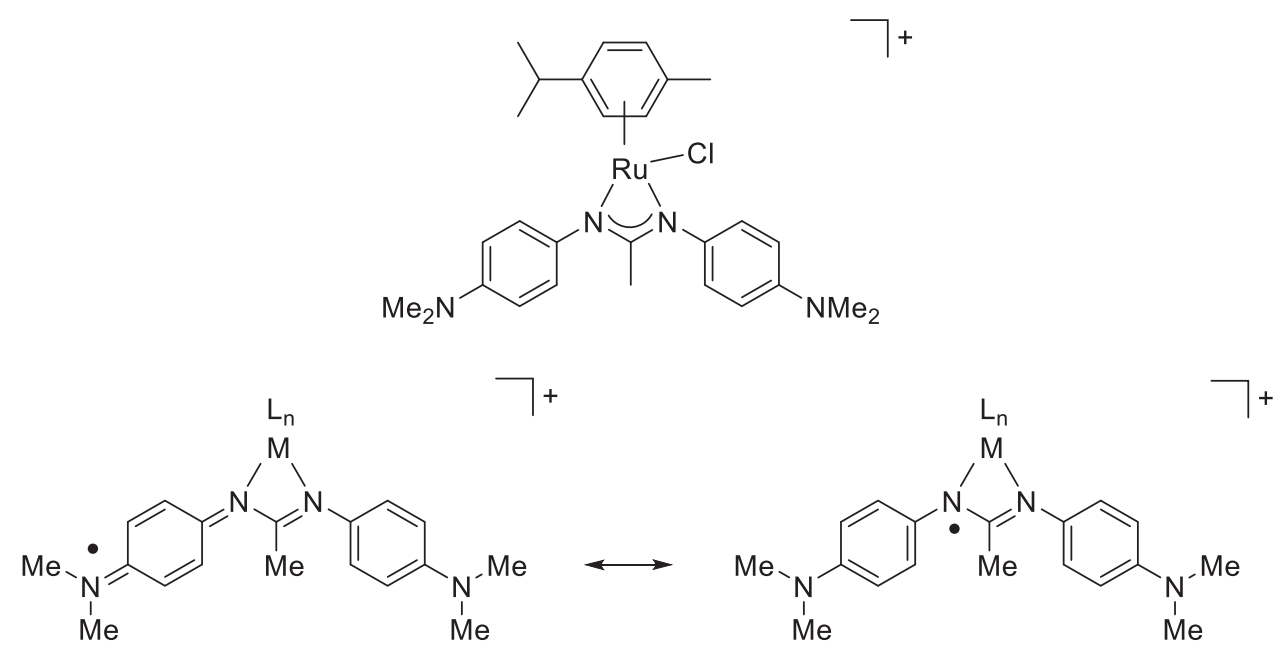

Figure 1. Two resonance formulations within a paramagnetic cationic complex. ${ }^{13}$

through metal coordination even if the main chromophore is the radical ligand. A recent example ${ }^{13}$ uses a new amidinato ligand forming a four-membered chelate ring with ruthenium (Figure 1) and exhibiting the rise of an intense ( $\varepsilon=30000 \mathrm{M}^{-1} \mathrm{~cm}^{-1}$ ) and relatively narrow absorption at $1230 \mathrm{~nm}$ on ligand centered oxidation (Figure 2). The latter is confirmed experimentally by EPR and theoretically through spin density calculations (Figure 3).

An alternative for dinuclear or oligonuclear complexes is the occurrence of metal-to-metal or inter-valence charge transfer transitions (MMCT, IVCT) between formally reduced and oxidized centers. ${ }^{14-17}$ Asymmetrical bonding such as in Prussian Blue with its (l.s.) $\mathrm{Fe}^{\mathrm{II}}-\mathrm{C} \equiv \mathrm{N}-\mathrm{Fe}^{\mathrm{III}}$ (h.s.) arrangement is the prime example for such a mixed-valent situation with low-energy transitions, even if this particular absorption is mostly visible, giving rise to the intense blue color. In contrast to such typical 'Class II' mixed-valent species $^{18}$ there are compounds clearly identified as symmetrical 'Class III' mixed-valent species, e.g., Mössbaueridentified $\mathrm{Fe}^{2.5}-(\mu-\mathrm{L})-\mathrm{Fe}^{2.5}$ compounds (Figure 4$)^{19}$ or the long debated ${ }^{14,20}$ Creutz-Taube ion with a $\mathrm{Ru}^{2.5}-\left(\mu-\mathrm{L}^{\prime}\right)$ $\mathrm{Ru}^{2.5}$ borderline situation (Figure 4$) .{ }^{20}$ In these strongly coupled cases, the near-infrared transition occurs between the bonding and the antibonding combination of metal orbitals.

Those cases (1) where a potentially mixed-valent dimetal pair is bridged by a potentially radical-forming 'non-innocent' ${ }^{21}$ ligand require further information from calculations or experiment (e.g., IR, Raman, EPR) in order to identify the site of low-energy electronic transition. While spin densities can normally be reliably calculated at the DFT level, the calculations of near-infrared transitions may be less straightforward.

$\mathrm{Ru}^{\mathrm{III}}-\left(\mu-\mathrm{L}^{2-}\right)-\mathrm{Ru}^{\mathrm{II}} \leftrightarrow \mathrm{Ru}^{\mathrm{II}}-\left(\mu-\mathrm{L}^{--}\right)-\mathrm{Ru}^{\mathrm{II}}$

The value of EPR data lies in the effect of metal participation at the spin distribution through its large spin-orbit

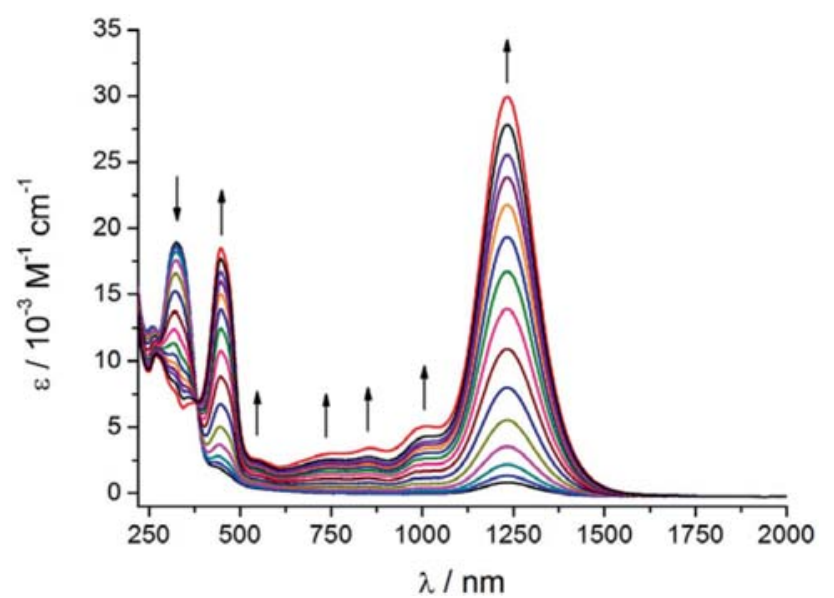

Figure 2. UV-vis-NIR spectroelectrochemical response on oxidation of the neutral to the cationic complex from Figure 1 in $\mathrm{CH}_{2} \mathrm{Cl}_{2} / 0.1 \mathrm{M} \mathrm{Bu}_{4} \mathrm{NPF}_{6}$.

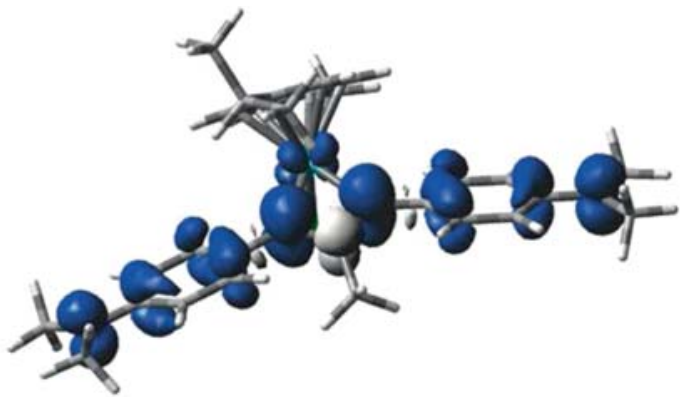

Figure 3. DFT calculated spin densities for the cation from Figure 1.

coupling. The result of strong metal participation is a significant deviation of the $g$ factor from 2.0023 for the free electron, ${ }^{22-24}$ in itself a consequence of relativistic effects. ${ }^{25}$ Both the isotropic $g$ value and the anisotropy of $g$ in immobilized form correlate with the amount of metal 
Creutz-Taube-Ion

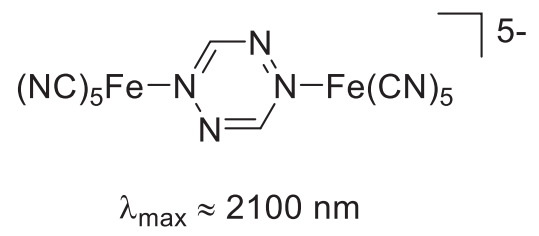

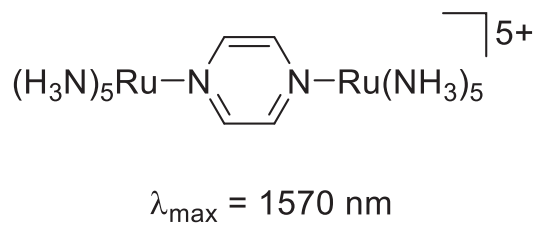

Figure 4. Two NIR absorbing mixed valent ions. ${ }^{19,20}$

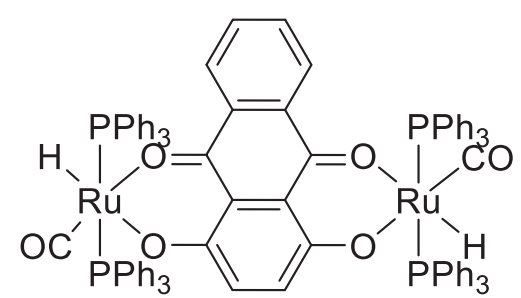

Figure 5. 1,4-Dioxido-9,10-anthraquinone precursor complex.

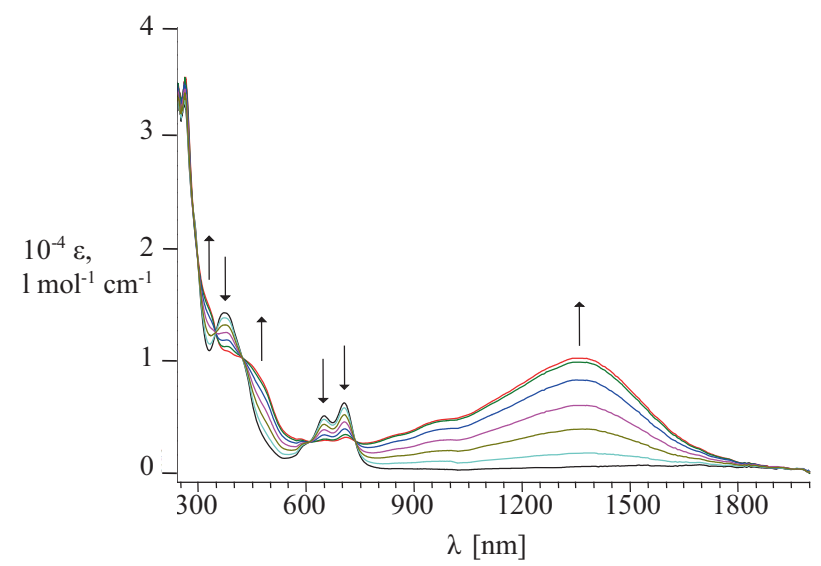

Figure 6. UV-vis-NIR spectroelectrochemical response on oxidation of the neutral to the cationic complex from Figure 5 in $\mathrm{CH}_{2} \mathrm{Cl}_{2} / 0.1 \mathrm{M} \mathrm{Bu}_{4} \mathrm{NPF}_{6}$. participation at the spin distribution and thus with the character of the corresponding electronic transition.

Quinonoid bridging ligands have been used with diruthenium complexes, often exhibiting intense near-infrared transitions. ${ }^{26}$ The example in Figures 5, 6 with strong absorption at $\lambda_{\max }=1370 \mathrm{~nm}$ after oxidation to the $(1+)$ form may suggest the formation of a mixed-valent species such as the Creutz-Taube ion (Figure 4). However, both the EPR and IR results from corresponding spectroelectrochemical experiments ${ }^{28,29}$ reveal very little metal contribution to the singly occupied MO, attributing the near IR transition to the $\pi$ system of the anthrasemiquinone bridge.

9,10-Anthraquinones are known as useful dyes even in the non-radical state, and the formation of metal-containing radical intermediates with NIR absorption thus creates a further attractive pathway to remarkable chromophores. ${ }^{27}$

Another class of potentially metal-binding dye functions includes modified azo compounds. These can be designed to bridge two metal ions ${ }^{30}$ introducing again the alternative of metal-metal mixed valency or radical formation to cause near-infrared absorption. ${ }^{7,26,31}$ Azodicarbonyl systems (hydrazido(2-) species in the two-electron reduced form, Figure 7) have been shown to bind ruthenium centers in bisbidentate fashion (Figure 7), with variable spin distribution $^{31}$ and useful electrochromical optical switching behavior in ranges of interest for telecommunication applications. ${ }^{32-39}$<smiles>[R]C(=O)N=NC([R])=O</smiles>

adc-R

(azo)

$\mathrm{d}_{\mathrm{N}-\mathrm{N}} \sim 1.25 \AA$<smiles>[R]C(=O)N=NC([R])=O</smiles>

$(\operatorname{adc}-\mathrm{R})^{\bullet-}$

$(\text { azo })^{\bullet-}$

$\sim 1.35 \AA$<smiles>[R]C(=O)[N-]NC([R])=O</smiles>

$(\text { adc-R })^{2-}$

(hydrazido) $^{2-}$

$\sim 1.42 \AA$

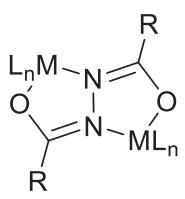

Figure 7. Two-step redox system based on adc-R ligands (top) and dinuclear metal complexes of (adc-R) ${ }^{2-}$ ligands (bottom). 


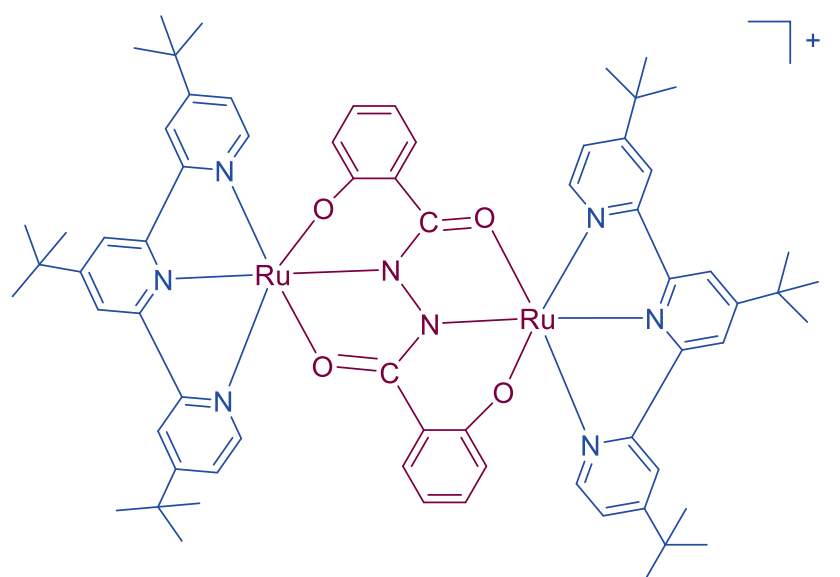

Figure 8. Bis(tridentate) chelating of the bridge in a paramagnetic diruthenium complex ion.

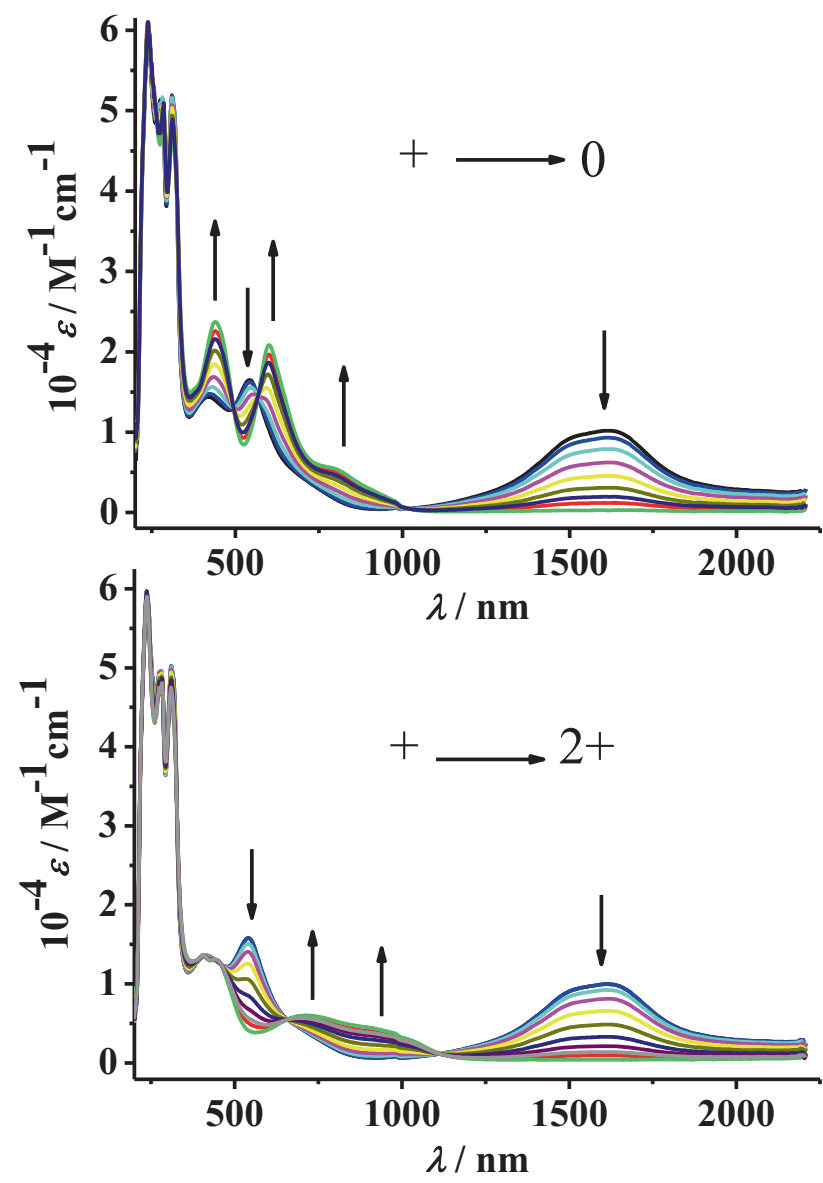

Figure 9. UV-vis-NIR spectroelectrochemical reduction and oxidation of the cation from Figure 8 in $\mathrm{CH}_{2} \mathrm{Cl}_{2} / 0.1 \mathrm{M}$ $\mathrm{Bu}_{4} \mathrm{NPF}_{6}$ at $298 \mathrm{~K}$.

A recent extension to a bis-tridentate bridging azo ligand has produced a complex redox system of which the paramagnetic cation absorbs at $1660 \mathrm{~nm}$ and $1530 \mathrm{~nm}$ (Figures 8,9$)^{34}$

EPR and DFT spin density calculations point again to a dimetal/bridge mixed spin situation in the singly occupied

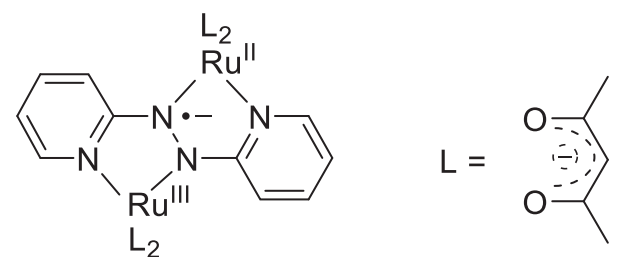

Figure 10. Radical anion-bridged mixed-valent compounds. $^{40}$

MO (SOMO), i.e., a resonance situation between a mixed valent and a radical formulation (1).

Such a resonance description (1) is related to formulation (2)

$\mathrm{Ru}^{\mathrm{III}}-\left(\mu-\mathrm{L}^{--}\right)-\mathrm{Ru}^{\mathrm{II}} \leftrightarrow \mathrm{Ru}^{2.5}-\left(\mu-\mathrm{L}^{--}\right)-\mathrm{Ru}^{2.5}$

which was evidenced by structural and computational studies for the diamagnetic compounds from Figure 10 (two diastereoisomers possible). ${ }^{40}$

Antiparallel spin-spin coupling accounts for the diamagnetism, and the intense near IR absorption occurs at 840 $\mathrm{nm}$, i.e., at relatively high energy. ${ }^{40}$

\section{Conclusions}

The increasing interest in near-infrared absorbing materials has prompted the need to develop concepts for stable molecular compounds with small frontier orbital gaps. Beyond empirically discovered examples, there are representative advanced classes of materials that can provide the necessary physical and chemical requirements, mostly due to a combination of electron delocalization and intramolecular charge transfer activity.

Making use of persistent odd-electron systems (radicals, mixed-valent arrangements), this article describes an ingenious way to achieve NIR absorption in attractive spectral regions that is provided by dinuclear (or oligonuclear) ${ }^{41,42}$ metal complexes with non-innocent bridging ligands, where mixed-valency and (2)/or (1) radical formation can lead to small frontier orbital differences and corresponding intense low energy transitions.

\section{Acknowledgements}

Support from the Deutsche Forschungsgemeinschaft, EU (COST D35) and Fonds der Chemischen Industrie is gratefully acknowledged. Special thanks are due to Mrs. Angela Winkelmann for her contributions in preparing this article and to Drs. J. Fiedler and S. Záliš (J. Heyrovsky Institute, Prague) for continued cooperation.

\section{References}

1. Bouit P-A, Wetzel G, Berginc G, Loiseaux B, Toupet L, Feneyrou P, Bretonniere Y, Kamada K, Maury O 
and Andraud C 2007 Near IR Nonlinear Absorbing Chromophores with Optical Limiting Properties at Telecommunication Wavelengths Chem. Mater. 19 5325

2. Wang L V and Wu H-I 2007 Biomedical Optics (Hoboken: Wiley)

3. Horvath H 1993 Atmospheric light absorption - A review Atmos. Environ. A 27293

4. Ozaki Y, McClure W F and Christy A A 2006 NearInfrared Spectroscopy in Food Science and Technology (Hoboken: Wiley)

5. Bundgaard E and Krebs F C 2007 Low band gap polymers for organic photovoltaics Sol. Energy Mater. Sol. Cells 91954

6. Fabian J, Nakazumi H and Matsuoka M 1982 NearInfrared Absorbing Dyes Chem. Rev. 921197

7. Kaim W 2011 Concepts for metal complex chromophors absorbing in the near infrared Coord. Chem. Rev. 2552503

8. Wang F, Lin T T, He C, Chi H, Tang T and Lai Y-H 2012 Azulene-containing Organic Chromophores with Tunable Near-IR Absorption in the Range of 0.6 to 1.7 mm J. Mater. Chem. 2210448

9. Mews N M, Berkefeld A, Hörner $G$ and Schubert $H$ 2017 Controlling Near-Infrared Chromophore Electronic Properties through Metal-Ligand Orbital Alignment J. Am. Chem. Soc. 1392808

10. He H 2014 Near-infrared emitting lanthanide complexes of porphyrin and BODIPY dyes Coord. Chem. Rev. 273-274 87

11. Otto S, Grabolle M, Förster C, Kreitner C, ReschGenger $U$ and Heinze K $2015\left[\mathrm{Cr}(\mathrm{ddpd})_{2}\right]^{3+}$ : A Molecular, Water-Soluble, Highly NIR-Emissive Ruby Analogue Angew. Chem. Int. Ed. 5411572

12. Shida T 1988 Electronic absorption spectra of radical ions (Amsterdam: Elsevier)

13. Ehret F, Bubrin M, Záliš S and Kaim W 2015 Metal Chelating N,N'-Bis(4-dimethylaminophenyl)acetamidinyl Radical: A new chromophore for the near infrared Chem. Eur. J. 2112275

14. Rocha R C, Rein F N, Jude H, Shreve A P, Concepcion J J and Meyer T J 2008 Observation of three intervalence-transfer bands for a Class II-III mixed-valence complex of ruthenium Angew. Chem. Int. Ed. 47503

15. D'Alessandro D M and Keene F R 2006 Current trends and future challenges in the experimental, theoretical and computational analysis of intervalence charge transfer (IVCT) transitions Chem. Soc. Rev. 35424

16. Kaim W, Klein A and Glöckle M 2000 Exploration of Mixed-Valence Chemistry: Inventing New Analogues of the Creutz-Taube Ion Acc. Chem. Res. 33755

17. Glover S D and Kubiak C P 2011 Persistence of the three-state description of mixed valency at the localized-to-delocalized transition J. Am. Chem. Soc. 133 8721

18. Robin M B and Day P 1968 Mixed Valence ChemistryA Survey and Classification Adv. Inorg. Chem. Radiochem. 10247

19. Glöckle M, Kaim W, Klein A, Roduner E, Hübner G, Záliš S, van Slageren J, Renz F and Gütlich P 2001 The Stable Diiron(2.5) Complex Ion $[(\mathrm{NC}) 5 \mathrm{Fe}(\mu-$ $\left.\mathrm{tz}) \mathrm{Fe}(\mathrm{CN})_{5}\right]^{5-}, \mathrm{tz}=1,2,4,5$-Tetrazine, and Its Neighboring Oxidation States Inorg. Chem. 402256

20. Creutz C 1983 Mixed valence complexes of $\mathrm{d}^{5}-\mathrm{d}^{6}$ metal centers Prog. Inorg. Chem. 301

21. Kaim W 2011 Manifestations of Non-innocent Ligand Behavior Inorg. Chem. 509752

22. Kaim W 2001 ESR Spectroscopy of Inorganic and Organometallic Radicals in Electron Transfer in Chemistry V Balzani (Ed.) (Weinheim: Wiley-VCH) Vol. 2 p. 976

23. Kaim W and Lahiri G K 2007 Unconventional MixedValent Complexes of Ruthenium and Osmium Angew. Chem. Int. Ed. 461778

24. Weil J A and Bolton J R 2007 Electron Paramagnetic Resonance $2^{\text {nd }}$ edn. (Hoboken: Wiley)

25. Autschbach J 2012 Perspective: Relativistic effects $J$. Chem. Phys. 136150902

26. Ernst S, Hänel P, Jordanov J, Kaim W, Kasack V and Roth E 1989 Stable Binuclear o- and p-Semiquinone Complexes of $\left[\mathrm{Ru}(\mathrm{bpy})_{2}\right]^{2+}$. Radical Ion versus Mixed Valence Dimer Formulation J. Am. Chem. Soc. 111 1733

27. Maji S, Sarkar B, Mobin S M, Fiedler J, Urbanos F A, Jimenez-Aparicio R, Kaim W and Lahiri G K 2008 Valence State Alternatives in Diastereoisomeric Complexes $\left[(\mathrm{acac})_{2} \mathrm{Ru}(\mu-\mathrm{QL}) \mathrm{Ru}(\mathrm{acac})_{2}\right]^{\mathrm{n}} \quad\left(\mathrm{QL}^{2-}=1,4-\right.$ Dioxido-9, 10-anthraquinone, $\mathrm{n}=+2,+1,0,-1,-2)$ Inorg. Chem. 475204

28. Kamatchi T S, Mondal S, Scherer T, Bubrin M, Natarajan K and Kaim W 2017 Near IR Absorbing Organometallic Diruthenium Complex Intermediates: Evidence for Bridging Anthrasemiquinone Formation and against Mixed Valency Chem. Eur. J. 2317810

29. Kaim W and Fiedler J 2009 Spectroelectrochemistry: the best of two worlds Chem. Soc. Rev. 383373

30. Kaim W 2001 Complexes with 2,2'-azobispyridine and related S-frame bridging ligands containing the azo function Coord. Chem. Rev. 219-221 463

31. Kasack V, Kaim W, Binder H, Jordanov J and Roth E 1995 When is an Odd-Electron Dinuclear Complex a Mixed-Valent Species? Tuning of Ligand-to-Metal Spin Shifts in Diruthenium Complexes of Non-Innocent Dicarbonylhy-drazido Bis-Chelate Ligands Inorg. Chem. 341924

32. Jana R, Sarkar B, Bubrin D, Fiedler J and Kaim W 2010 Structure, electrochemistry and spectroscopy of a new diacylhydrazido-bridged diruthenium complex with a strongly near-infrared absorbing $\mathrm{Ru}^{\mathrm{III}} \mathrm{Ru}{ }^{\mathrm{II}}$ intermediate Inorg. Chem. Commun. 131160

33. Roy S, Sarkar B, Imrich H-G, Fiedler J, Záliš S, Jimenez-Aparicio R, Urbanos F A, Mobin S M, Lahiri G K and Kaim W 2012 Charged but Found Not Guilty: Innocence of the Suspect Bridging Ligands $[\mathrm{RO}(\mathrm{O}) \mathrm{CNNC}(\mathrm{O}) \mathrm{OR}]^{2-}=\mathrm{L}^{2-}$ in $\left[(\mathrm{acac})_{2} \mathrm{Ru}(\mu-\right.$ L)Ru(acac $\left.)_{2}\right]^{\mathrm{n}}, \mathrm{n}=+, 0,-, 2-$ Inorg. Chem. 519273

34. Mondal S, Schwederski B, Frey W, Fiedler J, Záliš S and Kaim W 2018 At the Borderline between MetalMetal Mixed Valency and a Radical Bridge Situation: Four Charge States of a Diruthenium Complex with a Redox-active Bis(mer-tridentate) Ligand Inorg. Chem. 573983 
35. Qi Y, Desjardins P and Wang Z Y 2002 Novel nearinfrared active dinuclear ruthenium complex materials: Effects of substituents on optical attenuation J. Opt. A: Pure Appl. Opt. 4 S273

36. Wang Z Y, Zhang J, Wu X, Birau M, Yu G, Yu H, Qi Y, Desjardin P, Meng X, Gao J P, Todd E, Song N, Bai Y, Beaudin A M R and LeClair G 2004 Near-infrared absorbing organic materials Pure Appl. Chem. 761435

37. Xun S, LeClair G, Zhang J, Chen X, Gao J P and Wang Z Y 2006 Tuning the Electrical and Optical Properties of Dinuclear Ruthenium Complexes for Near Infrared Optical Sensing Org. Lett. 81697

38. Xun S, Zhang J, Li X, Ma D and Wang Z Y 2008 Synthesis and near-infrared luminescent properties of some ruthenium complexes Synth. Met. 158484

39. LeClair G and Wang Z Y 2009 Optical attenuation at the $1,550-\mathrm{nm}$ wavelength in a reflective mode using electrochromic ruthenium complex film J. Solid State Electrochem. 13365

40. Sarkar B, Patra S, Fiedler J, Sunoj R B, Janardanan D, Lahiri G K and Kaim W 2008 Mixed-Valent Metals Bridged by a Radical Ligand: Fact or Fiction Based on Structure-Oxidation State Correlations J. Am. Chem. Soc. 1303532

41. Záliš S, Sarkar B, Duboc C and Kaim W 2009 Evidence for the dimer-of-(mixed-valent dimers) configuration in tetranuclear $\left\{(\mu 4-\mathrm{TCNX})\left[\mathrm{Ru}\left(\mathrm{NH}_{3}\right)_{5}\right]_{4}\right\}^{8+}$, TCNX = TCNE and TCNQ, from DFT Calculations Chem. Monthly 140765

42. Ansari M A, Mandal A, Beyer K, Paretzki A, Schwederski B, Kaim W and Lahiri G K 2017 Non-Innocence and mixed valency in tri- and tetranuclear ruthenium complexes of a heteroquinone bridging ligand Dalton Trans. 4615589 